\title{
Vigorous achalasia: Zebra amongst horses
}

\begin{tabular}{|c|c|}
\hline \multicolumn{2}{|c|}{ 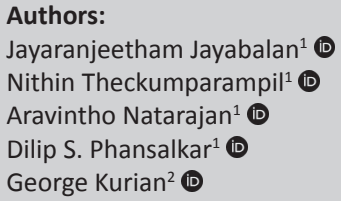 } \\
\hline \multicolumn{2}{|c|}{$\begin{array}{l}\text { Affiliations: } \\
{ }^{1} \text { Department of } \\
\text { Radiodiagnosis, Pondicherry } \\
\text { Institute of Medical Sciences, } \\
\text { Puducherry, India }\end{array}$} \\
\hline \multicolumn{2}{|c|}{$\begin{array}{l}{ }^{2} \text { Department of } \\
\text { Gastroenterology, } \\
\text { Pondicherry Institute of } \\
\text { Medical Sciences, } \\
\text { Puducherry, India }\end{array}$} \\
\hline \multicolumn{2}{|c|}{$\begin{array}{l}\text { Corresponding author: } \\
\text { Jayaranjeetham Jayabalan, } \\
\text { jayranji94@gmail.com }\end{array}$} \\
\hline $\begin{array}{l}\text { Dates: } \\
\text { Received: } 21 \\
\text { Accepted: } 09 \\
\text { Published: } 30\end{array}$ & $\begin{array}{l}\text { uly } 2020 \\
\text { Sept. } 2020 \\
\text { Nov. } 2020\end{array}$ \\
\hline \multicolumn{2}{|c|}{$\begin{array}{l}\text { How to cite this article: } \\
\text { Jayabalan J, } \\
\text { Theckumparampil N, } \\
\text { Natarajan A, Phansalkar DS, } \\
\text { Kurian G. Vigorous achalasia: } \\
\text { Zebra amongst horses. S Afr J } \\
\text { Rad. 2020;24(1), a1953. } \\
\text { https://doi.org/10.4102/sajr. } \\
\text { v24i1.1953 }\end{array}$} \\
\hline \multicolumn{2}{|c|}{$\begin{array}{l}\text { Copyright: } \\
\text { (C) 2020. The Author } \\
\text { Licensee: AOSIS. Thi } \\
\text { is licensed under the } \\
\text { Creative Commons } \\
\text { Attribution License. }\end{array}$} \\
\hline \multicolumn{2}{|l|}{ Read online: } \\
\hline 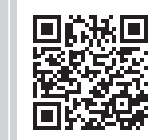 & $\begin{array}{l}\text { Scan this QR } \\
\text { code with your } \\
\text { smart phone or } \\
\text { mobile device } \\
\text { to read online. }\end{array}$ \\
\hline
\end{tabular}

\begin{abstract}
Vigorous achalasia is an oesophageal disorder with clinical and radiological characteristics of classic achalasia and diffuse oesophageal spasm. It is a rarely reported variant. A 60-year-old gentleman presented with complaints of difficulty in swallowing, regurgitation and chest pain for the past 10 years. His symptoms persisted despite the use of proton pump inhibitors. On endoscopy and barium swallow, the diagnosis of vigorous achalasia was confirmed. It is a rare variant of classic achalasia usually misdiagnosed as diffuse oesophageal spasm.

Keywords: vigorous achalasia; diffuse oesophageal spasm; classic achalasia; barium swallow; proton pump inhibitors.
\end{abstract}

\section{Introduction}

Classic achalasia and diffuse oesophageal spasm (DES) both have different clinical, radiological and manometric features. ${ }^{1}$ Chest pain is more common in DES, whereas it is uncommon in classic achalasia. Regurgitation and retention are more common in classic achalasia, whereas they are uncommon in DES. ${ }^{2}$ At barium swallow imaging, classic achalasia shows dilatation and DES demonstrates a corkscrew appearance. Motility studies indicate that DES and classic achalasia are at opposite ends of a spectrum. ${ }^{3}$ Diffuse oesophageal spasm responds less to treatment, unlike classic achalasia. ${ }^{4}$ Some individuals have a combination of the above-mentioned symptoms and cannot be placed under already established entities. ${ }^{2}$

In 1957, Olsen et al. first described the term vigorous achalasia in a group of individuals with classic achalasia whose clinical features and manometric features demonstrated common features of both classic achalasia and DES. ${ }^{5}$ According to Millan et al., ${ }^{3}$ vigorous achalasia falls in-between the two extremes (DES and classic achalasia) of the oesophageal motility disorder spectrum. ${ }^{3}$ This case illustrates the unusual oesophageal disorder of vigorous achalasia.

\section{Case description}

A 60-year-old male with no known comorbidities, presented with a 10-year history of difficulty in swallowing (liquids more than solids) and chest pain, which persisted despite the use of proton pump inhibitors. His physical examination and laboratory parameters were unremarkable. A barium swallow study was recommended, followed by upper gastro-intestinal (UGI) endoscopy.

During the barium swallow study (using Baritop powder 100\% w/v $250 \mathrm{~mL}$ ), the cervical and proximal part of the thoracic oesophagus showed normal passage of barium (Figure 1). The distal part of the thoracic oesophagus exhibited a few areas of narrowing and areas of dilatation proximal to the narrowed segments (Figure 2). Tertiary contractions were noted and the distal end of the esophagus displayed spindle-shaped tapering (Figure 3).

At UGI-endoscopy, (Olympus scope - size $2.8 \mathrm{~mm}$ ), the upper part of the oesophagus was mildly dilated but otherwise normal. The distal part revealed lower oesophageal sphincter (LES) stenosis with pooling of saliva proximal to it. There was difficulty in passing the UGI scope beyond the site of the stenosis (Figure 4).

\section{Discussion}

Vigorous achalasia is an unusual oesophageal disorder that has clinical and radiological characteristics of both achalasia and DES. ${ }^{5}$ According to one study, vigorous achalasia falls inbetween the two extremes (DES and classic achalasia) of the oesophageal motility disorder spectrum. ${ }^{3}$ Although manometry is the gold standard test for motility disorders, it is time consuming and not easily available. ${ }^{6,7}$ In this case the radiological findings were very clear. 

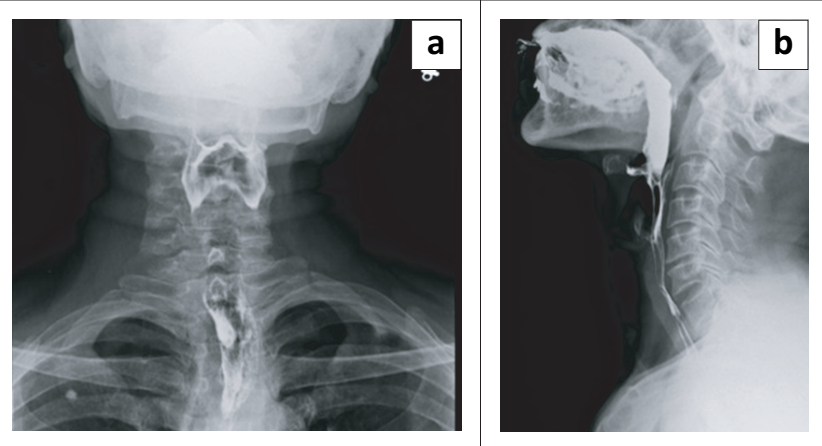

FIGURE 1: (a, b) Barium swallow Antero -posterior (AP) view and lateral view barium passed down the cervical and upper thoracic oesophagus smoothly and normally.

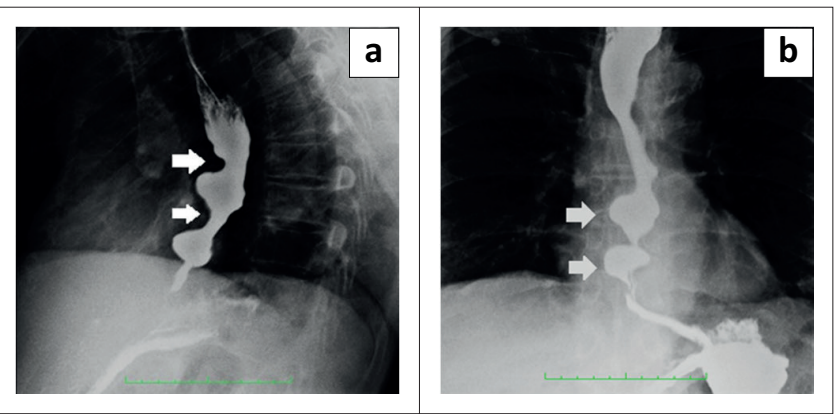

FIGURE 2: (a) Barium swallow Left anterior oblique (LAO) view - Arrows denote the areas of narrowing in the lower thoracic oesophagus. (b) Barium swallow Antero - posterior (AP) view - Arrows denote the areas of dilatation of the oesophagus proximal to the areas of narrowing.

\section{Classic achalasia versus vigorous achalasia}

Achalasia is an uncommon disorder that involves loss of inhibitory ganglions in the myenteric plexus of the LES and the body of the oesophagus. Over time, the progressive loss of cholinergic neurons results in dilation and low amplitude simultaneous contractions in the oesophageal body, resulting in classic achalasia. ${ }^{8}$

Regurgitation and retention are the most common symptoms in classic achalasia, whereas chest pain is uncommon. $^{2}$ At barium swallow imaging there will be proximal dilatation of the oesophagus with tapering ('bird beaking') of the lower end of the oesophagus. Classic achalasia is characterised by the complete absence of peristalsis. ${ }^{9}$ The diameter of the oesophageal body in vigorous achalasia is generally less than that of classic achalasia. As in our case of vigorous achalasia, there is minimal oesophageal dilatation with tertiary contractions and spindle-shaped tapering of the lower end of the oesophagus $^{10}$ (Figure 3).

Endoscopy of classic achalasia shows a dilated tortuous oesophagus with retention of fluid or food. ${ }^{11}$ The manometry study by Goldenberg et al. revealed that the amplitude is less than $37 \mathrm{~mm} \mathrm{Hg}$ in achalasia, whereas it is greater than or equal to $37 \mathrm{~mm} \mathrm{Hg}$ in patients with vigorous achalasia. ${ }^{12}$ Previous studies on the management of these conditions revealed that vigorous achalasia is less responsive to pneumatic dilatation when compared with

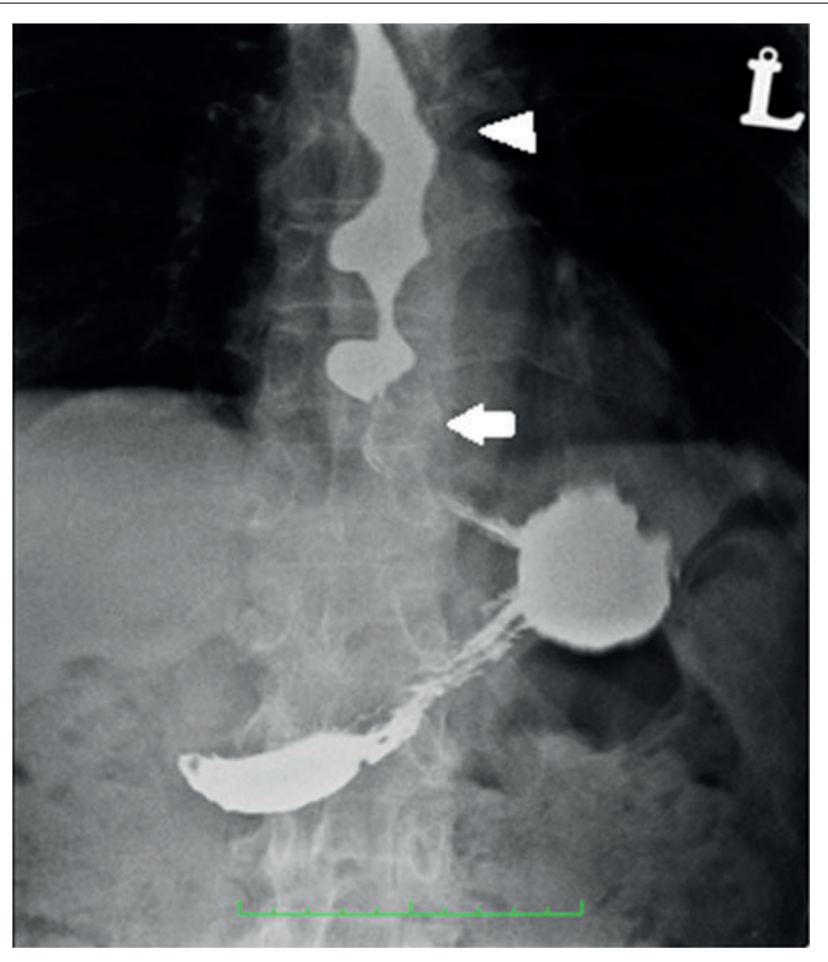

FIGURE 3: Barium swallow Antero - posterior (AP) view - Arrow denotes the spindle-shaped tapering of the lower end of the esophagus. Arrowhead denotes the tertiary contractions.

achalasia and have recommended surgery. ${ }^{2,13}$ In a study by Okike et al., ${ }^{14}$ the thoracic approach of an extended oesophageal myotomy of the oesophagus to the point where there are excess pressures and/or repetitive waves, was found to be better than pneumatic dilatation. Later, a study by Paricio et al. ${ }^{15}$ showed that Heller's myotomy, not extended to the oesophageal body, via an abdominal approach, also yields better results in vigorous achalasia as compared with classic achalasia. ${ }^{15}$ Peroral endoscopic myotomy (POEM) is a minimally invasive endoscopic treatment for symptomatic oesophageal achalasia. ${ }^{16}$ It was found to be effective in nearly $93.7 \%$ of patients with type III or vigorous achalasia. ${ }^{17}$

\section{Diffuse oesophageal spasm versus vigorous achalasia}

Diffuse oesophageal spasm (DES) is a rare motility disorder characterised by chest pain, dysphagia and intermittent increased simultaneous contractions. ${ }^{18}$ Impairment of the oesophageal inhibitory pathway results in premature contractions in the distal muscularis propria. Thus, the pathophysiology is similar to achalasia. ${ }^{19}$ Chest pain is the most common symptom in DES, whereas it is uncommon in vigorous achalasia. ${ }^{2}$ In our case, the patient experienced both dysphagia and chest pain. Physiologically, the studies on motility revealed that DES is the opposite of achalasia. ${ }^{3}$ Diffuse oesophageal spasm responds less to treatment, unlike achalasia. ${ }^{4}$

Endoscopy can sometimes show simultaneous ring-shaped contractions. $^{20}$ At barium swallow imaging, DES shows interruption of the normal peristalsis by multiple, repetitive, 

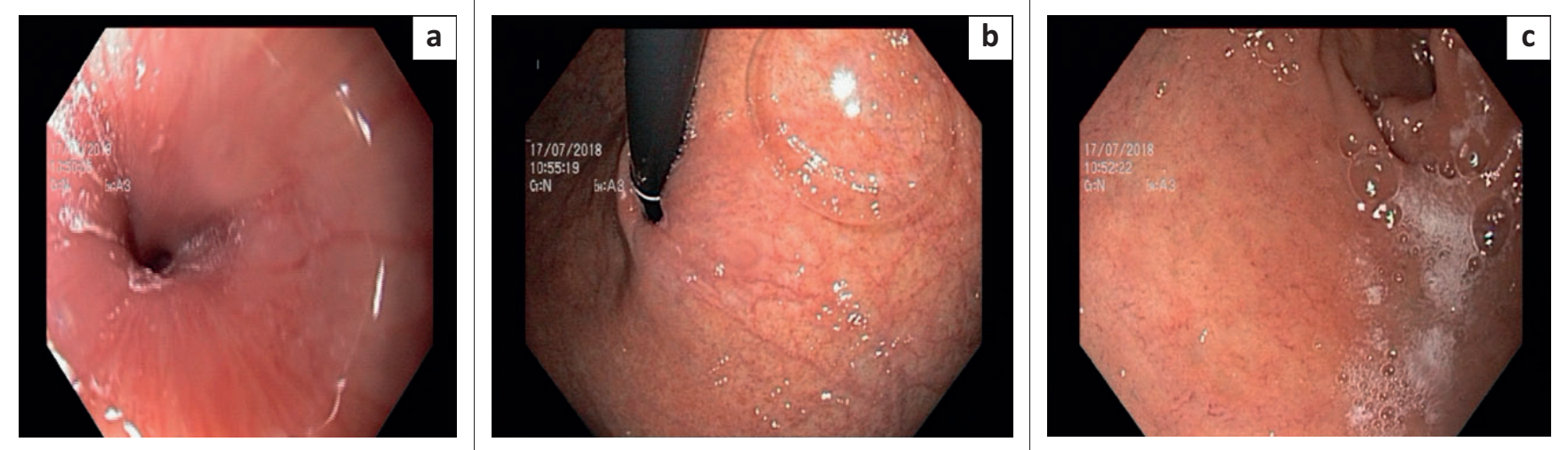

FIGURE 4: (a) Upper gastro-intestinal endoscopy - Shows the dilated proximal esophagus and stenotic lower oesophageal sphincter (b) Difficulty in passing the endoscope beyond the stenosis (c) Pooling of saliva above the stenotic lower oesophageal sphincter.

\begin{tabular}{|c|c|c|c|}
\hline Characteristics & Classic achalasia & $\begin{array}{l}\text { Diffuse } \\
\text { Oesophageal spasm }\end{array}$ & $\begin{array}{l}\text { Vigorous } \\
\text { achalasia }\end{array}$ \\
\hline Dysphagia & +++ & + & ++ \\
\hline $\begin{array}{l}\text { Regurgitation \& } \\
\text { retention of food }\end{array}$ & +++ & - & + \\
\hline Chest pain & $+/-$ & +++ & ++ \\
\hline \multicolumn{4}{|l|}{ Endoscopy } \\
\hline Oesophageal dilatation & +++ & - & + \\
\hline Retention of food & ++ & - & $+/-$ \\
\hline Passage of scope & $\begin{array}{l}\text { Difficulty } \\
\text { (depending on } \\
\text { grade of stenosis) }\end{array}$ & $\begin{array}{l}\text { Easy passage of } \\
\text { scope }\end{array}$ & $\begin{array}{l}\text { With difficulty } \\
\text { can be passed } \\
\text { through }\end{array}$ \\
\hline \multicolumn{4}{|l|}{ Barium swallow } \\
\hline Proximal \& mid part & $\begin{array}{l}\text { Dilated and } \\
\text { tortuous }\end{array}$ & $\begin{array}{l}\text { Corkscrew pattern } \\
\text { (Multiple } \\
\text { simultaneous } \\
\text { contractions with } \\
\text { intervening normal } \\
\text { peristalsis) }\end{array}$ & $\begin{array}{l}\text { Mildly dilated } \\
\text { with few tertiary } \\
\text { contractions }\end{array}$ \\
\hline Distal part & Bird beaking & Corkscrew pattern & Spindle-shaped \\
\hline Manometry amplitude & $<37 \mathrm{~mm} \mathrm{Hg}$. & $30 \mathrm{~mm} \mathrm{Hg}$ & $\geq 37 \mathrm{~mm} \mathrm{Hg}$ \\
\hline
\end{tabular}

non-propulsive oesophageal contractions (tertiary peristaltic waves) resulting in the characteristic corkscrew oesophagus. ${ }^{21}$ Manometric criteria includes the presence of simultaneous contractions in the distal (smooth muscle) oesophagus in more than $10 \%$ of wet swallows with an amplitude contraction of at least $30 \mathrm{~mm} \mathrm{Hg}$, alternating with normal peristalsis. ${ }^{22}$ Comparatively, vigorous achalasia is an atypical variant with non-peristaltic contractions giving the appearance of a corkscrew oesophagus on barium swallow ${ }^{23}$ (Figure 3).

The clinical features, imaging findings, endoscopic and manometric findings of oesophageal motility disorders are summarised in Table 1.

\section{Conclusion}

Vigorous achalasia is a rare oesophageal motility disorder, commonly misdiagnosed as DES. Knowledge and recognition of this uncommon entity will help in early recognition and optimal management.

\section{Acknowledgements Competing interests}

The authors have declared that no competing interests exist.

\section{Authors' contributions}

All authors contributed equally to this work.

\section{Funding information}

This research received no specific grant from any funding agency in the public, commercial or not-for-profit sectors.

\section{Ethical consideration}

This article followed all ethical standards for carrying out research.

\section{Data availability statement}

The authors confirm that the data supporting the findings of this study are available within the article.

\section{Disclaimer}

The views and opinions expressed in this article are those of the authors and do not necessarily reflect the official policy or position of any affiliated agency of the authors.

\section{References}

1. Castell DO. Achalasia and diffuse esophageal spasm. Arch Intern Med. 1976;136(5):571-579. https://doi.org/10.1001/archinte.1976.03630050053010

2. Sanderson DR, Ellis FH, Schlegel JF, Olsen AM. Syndrome of vigorous achalasia: Clinical and physiologic observations. Dis Chest. 1967; 52(4):508-517. https://doi. org/10.1378/chest.52.4.508

3. Millan MS, Bourdages R, Beck IT, DaCosta LR. Transition from diffuse esophageal spasm to achalasia. J Clin Gastroenterol. 1979;1(2):107-117. https://doi. spasm to achalasia. J Clin Gastroente
org/10.1097/00004836-197906000-00003

4. Olsen AM, Ellis FH, Creamer B. Cardiospasm (achalasia of the cardia). Am J Surg. 1957;93(2):299-307. https://doi.org/10.1016/0002-9610(57)90782-1

5. What is vigorous achalasia ? [homepage on the Internet]. [cited 2020 May 19]. Available from: http://www.oeso.org/OESO/books/Vol_4_Prim_Motility/Articles/ ART122.HTM

6. Cohen S, Motor disorders of the esophagus. N Engl J Med. 1979;301(20): 1124-1125. https://doi.org/10.1056/NEJM197911153012016

7. Schima $W$, Ryan JM, Harisinghani M, et al. Radiographic detection of achalasia: Diagnostic accuracy of videofluoroscopy. Clin Radiol. 1998;53(5):372-375. https://doi.org/10.1016/S0009-9260(98)80012-3

8. Ghoshal UC, Daschakraborty SB, Singh R. Pathogenesis of achalasia cardia. World J Gastroenterol. 2012;18(24):3050-3057. https://doi.org/10.3748/wjg.v18.i24.3050

9. Camacho-Lobato L, Katz PO, Eveland J, Vela M, Castell DO. Vigorous achalasia: Original description requires minor change. J Clin Gastroenterol. 2001;33(5): 375-377. https://doi.org/10.1097/00004836-200111000-00006 (1)

10. Rhee $\mathrm{K}$, Jeon $\mathrm{H}$, Kim J-H, Yoon YH, Park H, Lee SI. An evidence of esophagea decompensation in patients with achalasia in the view of its subtype: A retrospective study. J Neurogastroenterol Motil. 2013;19(3):319-323. https://doi org/10.5056/jnm.2013.19.3.319 
11. McCormick SE, Kozarek RA. Endoscopic evaluation of esophageal motility disorders. GI Motil Online [serial online]. 2006 [cited 2020 May 25]. Available from: https://www.nature.com/gimo/contents/pt1/full/gimo29.html

12. Goldenberg SP, Burrell M, Fette GG, Vos C, Traube M. Classic and vigorous achalasia: A comparison of manometric, radiographic, and clinical findings. Gastroenterology. 1991;101(3):743-748. https://doi.org/10.1016/0016-5085(91) 90534-R

13. Giuli R. O.E.S.O. the Esophagogastric: The Esophagogastric Junction. Arcueil: John Libbey Eurotext; 1998, p. 1674.

14. Okike N, Payne WS, Neufeld DM, Bernatz PE, Pairolero PC, Sanderson DR Esophagomyotomy versus forceful dilation for achalasia of the esophagus: Results
in 899 patients. Ann Thorac Surg. 1979;28(2):119-125. https://doi.org/10.1016/ in 899 patients. Ann Tho
S0003-4975(10)63767-8

15. Parrilla Paricio P, Martinez de Haro LF, Ortiz Escandell A, Morales Cuenca G, Molina Martinez J. Short myotomy for vigorous achalasia. $\mathrm{Br} J$ Surg. 1993;80(12):1540-1542. https://doi.org/10.1002/bjs.1800801215

16. Eleftheriadis $\mathrm{N}$, Inoue $\mathrm{H}$, Ikeda $\mathrm{H}$, et al. Training in peroral endoscopic myotomy (POEM) for esophageal achalasia. Ther Clin Risk Manag. 2012;8:329-342. https:// doi.org/10.2147/TCRM.S32666
17. POEM effective in spastic esophageal disorders [homepage on the Internet] [cited 2020 Sep 4]. Available from: https://www.healio.com/news/ gastroenterology/20190613/poem-effective-in-spastic-esophageal-disorders

18. Patel DA, Vaezi MF. A spiraling case of persistent dysphagia. Gastroenterology 2015;149(2):298-299. https://doi.org/10.1053/j.gastro.2015.04.049

19. Roman S, Kahrilas PJ. Distal esophageal spasm. Curr Opin Gastroenterol. 2015;31(4):328-333. https://doi.org/10.1097/MOG.0000000000000187

20. Kato T, Naiki T, Araki H, Nagaki M, Moriwaki H. Diffuse esophageal spasm. Gastrointest Endosc. 2004;60(4):428. https://doi.org/10.1016/S0016-5107(04) 01706-7

21. Carucci LR, Turner MA. Dysphagia revisited: Common and unusual causes. Radiog Rev Publ Radiol Soc N Am Inc. 2015;35(1):105-122. https://doi.org/10.1148/ rg.351130150

22. Achem SR. Diffuse esophageal spasm in the era of high-resolution manometry. Gastroenterol Hepatol. 2014;10(2):130-133.

23. Del PozoCalzada C, Molina Llorente H, González Gutiérrez M. Vigorous achalasia. Med Clin (Barc). 2018;150(3):124. https://doi.org/10.1016/j.medcli.2017.03.019 